\begin{tabular}{|l|l|}
\hline $\begin{array}{l}\text { ESCOLA DE COMUNICAÇÃO, } \\
\text { ARTES E DESIGN }\end{array}$ & $\begin{array}{l}\text { mídia, cultura e tecnologia } \\
\text { Revista FAMECOS, Porto Alegre, v. 28, p. 1-5, jan.-dez. } 2021 \\
\text { PUCRS }\end{array}$ \\
\hline $\begin{array}{l}\text { FAMECOS } \\
\text { e-ISSN: 1980-3729 | ISSN-L: 1415-0549 }\end{array}$ \\
\hline https://dx.doi.org/10.15448/1980-3729.2021.1.40040
\end{tabular}

PENSAMENTO MIDIÁTICO COMUNICACIONAL

\title{
Complexidade em diálogos com Edgar Morin
}

\author{
Complexity in dialogues with Edgar Morin \\ Complejidad en los diálogos con Edgar Morin
}

\section{Juremir Machado da \\ Silva ${ }^{1}$ \\ orcid.org/0000-0001-8105-5596 \\ juremir@pucrs.br}

Recebido em: 29 jan. 2021.

Aprovado em: 21 maio 2021.

Publicado em: 30 jun. 2021.
Resumo: Como praticar a complexidade defendida por Edgar Morin em tempos de simplificação nos campos político, científico e ideológico? Pode-se compreender essa complexidade nem sempre fácil por meio de entrevistas ao longo do tempo com o teórico da complexidade?

Palavras-chave: Complexidade. Edgar Morin. Imaginário.

Abstract: How to practice the complexity defended by Edgar Morin in times of simplification in the political, scientific and ideological fields? Can this complexity not always be easily understood through interviews over time with the complexity theorist?

Keywords: Complexity. Edgar Morin. Imaginary.

Resumen: ¿Cómo practicar la complejidad defendida por Edgar Morin en tiempos de simplificación en los campos político, científico e ideológico? ¿No siempre se puede comprender fácilmente esta complejidad a través de entrevistas con el teórico de la complejidad a lo largo del tiempo?

Palabras clave: Complejidad. Edgar Morin. Imaginario.

\section{Um conceito?}

O negacionismo defendido por muitos durante a pandemia do coronavirus indica que a complexidade vem perdendo terreno para as simplificações? Provavelmente. Mas o que é mesmo a complexidade? Edgar Morin, intelectual que tem refletido sobre o conhecimento complexo, numa entrevista que fiz com ele em 1993, afastava a possibilidade de a complexidade produzir simplificação como um efeito perverso da vasta gama de dados que podem ser envolvidos numa comunicação:

O pensamento tradicional cartesiano enfrenta um problema dividindo-o em pequenos pedaços. O pensamento complexo foi bem formulado por Pascal, que disse: 'Todas as coisas estão ligadas, são causas e consequências, mediatas e imediatas, e tudo se associa através de um laço insensivel, o mais distante e o mais próximo'. A chave do pensamento complexo é a inter-relação. Não podemos tudo saber, mas precisamos de um conhecimento que conheça seus limites e que trabalhe com a incerteza própria do real e antagônica aos determinismos. 
Complexo é o que tece muitos fios ao mesmo tempo e deixa aberto o desenho do tecido para novas configurações e possibilidades. A divisa dessa dinâmica poderia ser esta: ousar juntar para tentar saber. Em lugar de analisar o separado, observar a inter-relação, a zona hachurada. Tal perspectiva desconfia mais das certezas do que se assusta com a incerteza, reconhece a força do acaso e teme os determinismos sufocantes. Ao longo de quase 30 anos, no Brasil e na França, tenho entrevistado Edgar Morin. Em 1993, na conversa já citada, ele denunciava o esgotamento do modelo universitário:

A universidade não está em crise. Ela está inteiramente esclerosada. Repete-se a situação pela qual passou a universidade da Idade Média quando nasceu a ciência moderna. Foram necessários dois séculos para que a reforma se concretizasse. A universidade de hoje separou o conhecimento em disciplinas que não conseguem se comunicar. Trata-se de uma instituição que produz uma nova forma de concretização. Temos a cretinização vinda de baixo, dos meios de comunicação, e do alto, vinda da universidade. Precisamos mudar nosso modo de pensar. Por isso, defendo a ideia do pensamento complexo, multidimensional e global. ${ }^{3}$

Os termos eram fortes, duros, ácidos. De lá para cá muitas universidades têm buscado o caminho da inter ou da transdisciplinaridade. $\mathrm{Na}$ interdisciplinaridade, matérias colaboram. Na transdisciplinaridade, fundem-se. A reforma do pensamento e do modo de produção do saber continua. Talvez não sejam necessários dois séculos para a transformação acontecer. Tudo depende da determinação e da capacidade de comunicação dos produtores atuais de conhecimento. O grande inimigo é o burocrata, o tecnocrata do saber, o fiscal das regras, o zelador, aquele que deve impor o respeito ao paradigma.

Publiquei, em 1998, novo livro de diálogos com grandes intelectuais. Edgar Morin figurava novamente como entrevistado. Enfrentou a questão simples que ainda me parece incontornável: O que é a complexidade? A busca do complexo não deveria ser sempre o objetivo (assim como um método de pesquisa) de toda ciência? Respondeu assim:
O problema não é a busca, mas a necessidade de responder ao desafio da complexidade. Em contrapartida, eu diria que o pensamento complexo tira sentido da palavra latina complexus: tecido junto. Trata-se do pensamento que liga os conhecimentos separados. Por que ligar? Porque o conhecimento só é pertinente quando situado no seu contexto e na globalidade. Ligar, contextualizar e globalizar fazem parte da necessidade natural do conhecimento. Para saber ligar, entretanto, é preciso utilizar instrumentos de pensamento estranhos aos procedimentos científicos clássicos, que obedecem à causalidade linear simples, a uma lógica rígida e que obedecem sobretudo ao princípio de separação. O homem, por exemplo, que é ao mesmo tempo um ser físico, químico, cerebral, mental, espiritual, social e cultural, é estudado de maneira fragmentada: a física, a química, a biologia, o cérebro, o espírito, a cultura e a sociedade, a psicologia, etc. Ora, em realidade essa separação não nos permite compreender a complexidade humana. O pensamento complexo reage contra essa situação, sem ser, contudo, apenas o contrário do pensamento simples, e integra os modos de pensar simples e complexos numa concepção mais rica. Trata-se da « dialógica » do simples e do complexo, do separável e do não-separável, da ordem e da desordem, da 'dialógica' entre a lógica clássica e a transgressão lógica quando esta se impõe, ou antes entre a lógica clássica e a racionalidade aberta. Não se pode, portanto, aprender o pensamento complexo, sobretudo quando se tem a formação de um sistema reducionista, em um dia. A complexidade exige um novo e difícil aprendizado e a reforma do pensamento, a qual demanda a reforma da educação. ${ }^{4}$

O desafio permanece. As respostas dadas atualmente estão à altura das necessidades e expectativas? A complexidade é um conceito ou uma estratégia de construção de conhecimento? Na sua resposta, Morin fala em ligar, contextualizar, globalizar. Ele provoca o sistema refém das especializações que fragmentam sempre mais o que deve ser analisado. Não se constrange em chamar de reducionistas as formas tradicionais de organizar os modelos de produção de saber. Indica que para avançar é preciso saber transgredir, romper fronteiras, dar saltos epistemológicos. Trata-se de um estímulo entusiasmado ou de uma orientação capaz de encontrar a sua aplicabilidade concreta e fértil?

É possivel ser complexo no dia a dia de uma universidade e das pesquisas controladas por

\footnotetext{
3 Ibidem, p. 229.

4 SILVA, Juremir Machado da. O mestre da complexidade. In: SILVA, Juremir Machado da. Visões de uma certa Europa. Porto Alegre: Edipucrs, 1998. p. 68.
} 
rígidos protocolos de avaliação? Como ser complexo e global quando tudo é complicado e exige conhecimentos minuciosos sobre muito pouco para não se cair em generalizações ou superficialidades? O diálogo com um mestre deve ser feito de indagações sinceras e até ingênuas. Não se pode voltar para casa com a pergunta não feita por vergonha de parecer simplificador ou simplório. Para pensar diferente é preciso começar a pensar diferente. Tautologia? Impasse? Aporia? Contradição? Paradoxo? Edgar Morin examina a questão com perceptivel prazer intelectual. Pondera:

Existem dois tipos de pensamento fechados: há o isolamento nacionalista, religioso ou étnico, que só deseja ver o fragmento de humanidade por ele representado, ignorando o resto. Há também o fechamento próprio à tecnocracia, que só vê as dimensões quantitativas, econômicas, e esquece as outras facetas humanas. Como estamos no reino do pensamento mutilador ou fragmentário, a necessidade de contextualizar os problemas é de fato vital. De que forma? Todas as reformas começam marginalmente na medida em que existe uma contradição: como reformar os espíritos sem reformar antes o ensino e por consequência as instituições? Mas como reformar as instituições sem reformar antes os espíritos? É um círculo vicioso. As grandes reformas começam sempre pela tomada de decisão em algum lugar de criar uma nova instituição, nova experiência, na escola primária, secundária ou na universidade. Se a experiência mostra-se fecunda, pode generalizar-se. A universidade, por exemplo, foi teológica praticamente até o fim do século XVIII. A primeira universidade moderna, fundada sobre disciplinas, surgiu em Berlim no início do século XIX, num Estado periférico que era a Prússia; depois, esse modelo expandiu-se. Hoje, é preciso inventar um novo modelo e. como as necessidades da época exigem outro modo de pensar, ele terá chances de impor-se. O mesmo vale para a escola primária: seria preciso começar por uma reforma de ensino que partisse das questões fundamentais - quem somos? De onde viemos? Para onde vamos? e então ligar os conhecimentos de diferentes disciplinas. Vejo a possibilidade da reforma, mas toda evolução inicia por um desvio, por alguma coisa não ortodoxa e minoritária. É inevitável. ${ }^{5}$

Para bom entendedor, uma resposta dessas basta. Não há fórmula. Seria um contrassenso. A reforma é uma brecha imprevista que se abre. Não há manual da revolução. O ensino era "primário". Tornou-se "fundamental". Era "secundário". Passou a ser "médio".
Essas nomenclaturas novas poderiam ser vistas como modestas pistas de uma transformação em curso? A mudança exige um desvio, que, obviamente, não pode ser planejado nem encomendado a consultores especializados. No passado, o "impossivel" aconteceu. A heresia corroeu o canônico. O marginal tomou o poder e virou central. O paradigma resistiu, censurou, perseguiu, puniu, estigmatizoue, finalmente, tombou. Por que não tombaria de novo? A ruptura tem um custo. Não é indolor.

\section{Caminhadas}

Não pergunte o caminho. Faça caminhadas. Caminhe. Para onde? Em que direção? As metodologias devem indicar rumos seguros. O método tem mais a ver com a caminhada. Conta-se depois de ter sido realizada. A reforma do pensamento, que tornará complexa a aventura do conhecimento, será uma caminhada a ser feita sem metodologia prévia, sem GPS, sem roteiro fechado e sem o parecer de um especialista. Como então embarcar em algo tão arriscado? Como se atrever a sair do trilho? Como enfrentar o vigia que circula com o regulamento em mãos? O quantitativo, com suas métricas especulares, é tão confortável.

O quantitativo, porém, deve ter o seu lugar. Saber, por exemplo, que a população menos representada no parlamento brasileiro é a negra tem grande valia. Abre a porta para a interpretação. Por quê? Exige a investigação do contexto, o conhecimento da história, a análise das narrativas, o desvelamento do cotidiano, a desconstrução de mitos. Em 2015, entrevistei Edgar Morin mais uma vez. Convidei-o a fazer o balanço da sua luta contra a simplificação e em defesa da complexidade. Perguntei-lhe se a reforma do pensamento avançava:

Não. Infelizmente. É algo bastante difícil. Sim, mas apenas de modo disperso. Na América Latina, no México, minhas ideias são aplicadas numa instituição. Falta, de maneira geral, uma base pedagógica institucional para desenvolver o que tenho defendido em meus livros sobre a complexidade.

Ele vinha de publicar na França A aventura de O método. Havia pessimismo e otimismo na sua 
avaliação aos 94 anos de idade. Lamentava-se o lento avanço da reforma do pensamento, destacava o quanto havia produzido o que o produzia e permitia que pensasse o mundo.

Meu objetivo com este novo livro foi mostrar como me veio a ideia de um método capaz de considerar a necessidade de complexidade para entender os fenômenos humanos e sociais. Tomei como símbolo uma árvore cujos galhos tocam no chão e se tornam raizes. Surge um novo tronco. O pensamento complexo é recursivo. Ele se alimenta também de si mesmo e se recria todo tempo. Ao descobrir o meu método, ele se voltou sobre o meu pensamento me obrigando a pensar nas suas consequências políticas, pedagógicos e filosóficas. Eu produzi um método, que, por seu turno, me produziu ao longo da vida. ${ }^{6}$

Produção e autoprodução. O produtor, como Morin não se cansa de mostrar, também ajuda a produzir aquilo que o produz. Há um vaivém incessante entre elementos que se afetam mutuamente. O pesquisador que volta inalterado da sua pesquisa não pesquisou de fato. Ou não se abriu para os resultados da sua investigação. Nesse sentido, não deixou a recursividade realizar-se. Blindou-se contra o retorno daquilo que descobriu (destapou, deu a ver, fez emergir). Complexo é aquilo que abraça uma variedade de ramos e bifurcações.

\section{Projeto}

Praticar a complexidade parece exigir uma busca permanente pelo conhecimento e pelo autoconhecimento sem um prazo para fazer cessar os efeitos. Implica pensar até que ponto se é dominado pelos pensamentos, fantasmas e ideias ou se tem liberdade para sonhar, mudar de pensamento, romper com fantasmas e mudar de ideias.

A noosfera está em nós assim como estamos nela. Mais ainda, a noosfera saiu inteira das nossas almas e dos nossos espíritos. Os mitos adquiriram forma, consistência, realidade, a partir de fantasmas formados pelos nossos sonhos e pelas nossas imaginações. As ideias ganharam forma, consistência, realidade, a partir dos simbolos e dos pensamentos das nossas inteligências (MORIN, 1998, p. 306).
Essa ideia simples, mas complexa, de estar naquilo que está no sujeito que observa implica uma tomada de posição movediça como se o ser fosse onda e partícula ao mesmo tempo. 0 ser não é. O ser está. O ser não termina. Ele se faz e refaz. Viver de fantasmas, de fantasias e de imaginação. Viver nos fantasmas, nas fantasias e na imaginação. Viver nas ideias, das ideias, pelas ideias, como uma ideia. Viver concretamente no imaginário e imaginariamente no concreto. Eis um labirinto de possibilidades que se oferece ao caminhante. Complexidade é movimento, laço, amplitude, conjunto, contexto, globalidade.

Nada mais complicado do que a complexidade, que deveria ser simples? Nem tanto. Ser complexo é buscar, ao mesmo tempo, a explicação (racional, lógica, abstrata) e a compreensão (concreta, relacionada à empatia, ao procedimento de colocar-se no outro). A complexidade exige pensar o universal e o particular num mesmo movimento. Ou pensar o abstrato pelo concreto, unidade e diversidade, unidade na diversidade, pluralidade e identidade. No seu livro Minha esquerda (2011), Morin dá uma mostra dessa unidade na multiplicidade e dessa multiplicidade unitária tão humana. A epigrafe já diz tudo: "Eu sou um direitista de esquerda. Direitista porque valorizo muito as liberdades, mas, ao mesmo tempo, sou muito esquerdista, pois tenho a convicção de que nossa sociedade precisa de transformações profundas e radicais. Tornei-me um conservador revolucionário. Precisamos revolucionar tudo, mas conservando os tesouros da nossa cultura".

Capturar a complexidade tem algo de inapreensivel: o complexo exige certa natureza fugidia, o que pode aborrecer os espíritos mais objetivos e utilitaristas. Como se contentar, num universo de formação cartesiana, com a subjetividade de uma estrutura que se propõe mais completa e se destaca pela ambiguidade. Pode-se, por hipótese, pensar a complexidade, sem que Edgar Morin possa ser responsabilizado por isso, como um projeto, aquilo que se fixa no tempo futuro, 
no momento posterior ao da nomeação, meta a ser alcançada pelo esforço da busca. Há outros projetos desse tipo: a busca do consenso numa comunidade de diálogo é um horizonte que se tenta alcançar com a certeza de que os horizontes são inalcançáveis, mas nem por isso menos necessários ao movimento da perseguição. Por vez, a caminhada só existe pelo caminho.

O que isso significa? Muito simples: que a determinação em tornar complexo já torna em algum grau mais complexo. O problema está no fato de que a simplificação, institucionalizada como método, enrijece o raciocínio e não abertura para a triade: contextualização-globalização-complexificação. Não se imagine um medidor de complexidade simples de usar e capaz de dirimir todas as dúvidas. Os hospitais podem ser organizados em baixa, média e alta complexidade. Há fenômenos, como amor, que cabem mais na métrica da poesia do que nos instrumentos da psicologia. O que fazer? Jogá-los para baixo do tapete da ciência com a conformada justificativa da impossibilidade de responder ao que não deve ser perguntado aos cientistas?

Edgar Morin diz que um dos autores a mudar a sua vida foi Michel de Montaigne. Nos seus Ensaios, datados do nem tão distante ano de 1580, o pensador legitimava o escrever sobre a própria vida como um ato de reflexão capaz de, na sua magnífica simplicidade não admitida, abrir portas para a compreensão do vivido. Montaigne (1996, p. 31):

Quero que me vejam aqui em meu modo simples, natural e corrente, sem pose nem artificio: pois é a mim que retrato. Meus defeitos, minhas imperfeições e minha forma natural de ser hão de se ler ao vivo, tanto quanto a decência pública me permitiu. Pois se eu estivesse entre essas nações que se diz ainda viverem sob a doce liberdade das leis primitivas da natureza, asseguro-te que teria com muito gosto me pintado por inteiro e totalmente nu. Assim, Leitor, sou eu mesmo a matéria de meu livro: não é razão para que empregues teu vagar em assunto tão frivolo e vão. Portanto, adeus.

Complexo não é o que se esconde no hermetismo da forma indecifrável. Pode ser aquilo que se dá a ver pela clareza do formulado. Falar de si não pode ser reduzido a um egocentrismo. Se não funciona, como muitas vezes acontece, pode ter mais a ver com a incompetência do autor para escrever do que com o tema proposto. O indivíduo (parte) está na espécie/humanidade (todo), que está na parte. Morin tem praticado a complexidade que defende e teoriza ao implicar-se na sua obra e ao revelar-se nas suas entrevistas. Ele não se envergonha em despir-se das pompas intelectuais diante do leitor. Numa entrevista, olhares se cruzam, frestas se abrem, pontos se mostram, visões de mundo se exibem, o singular entra em foco, uno e diverso se articulam em conjuntos que só fazem sentido quanto interpretados. No vão entre as duas vistas, do entrevistador e do entrevistado, desfila a complexidade do encontro e do diálogo.

\section{Referências}

MONTAIGNE, Michel. Ensaios. São Paulo: Nova Cultural, 1996.

MORIN, Edgar. A aventura de O Método. São Paulo: SESC, 2020.

MORIN, Edgar. A minha esquerda. Porto Alegre: Sulina, 2011.

MORIN, Edgar. O Método 4. As ideias. Porto Alegre: Sulina, 1998.

SILVA, Juremir Machado da. Visões de uma certa Europa. Porto Alegre: Edipucrs, 1998.

SILVA, Juremir Machado da. O pensamento do fim do século. Porto Alegre: L\&PM, 1993.

\section{Juremir Machado da Silva}

Doutor em Sociologia pela Université Paris $\vee$ René Descartes, em Paris, França. DEA em Sociologia Université Paris Descartes, em Paris, França. Graduado em Jornalismo e História pela Pontifícia Universidade Católica do Rio Grande do Sul (PUCRS), em Porto Alegre, RS, Brasil; professor titular da PUCRS onde coordenou, de 2003 a 2014, o Programa de Pós-Graduação em Comunicação. Pesquisador do CNPq 1B.

\section{Endereço para correspondência}

Juremir Machado da Silva

Pontifícia Universidade Católica do Rio Grande do Sul Av. Ipiranga, 6681, Prédio 7

Partenon, 97010-082

Porto Alegre, RS, Brasil

Os textos deste artigo foram revisados pela Poá Comunicação e submetidos para validação do autor antes da publicação 